\section{Whole Exome Sequencing: The Tip of the Iceberg}

Sir,

For many patients suffering from genetic diseases, an early diagnosis will allow appropriate management of the disease and increase the quality of life of most cases. Up to $85 \%$ of the causal variants involved in the etiopathogenesis of genetic diseases are localised in the coding and functional part, which occupies only $3 \%$ of the human genome. One of the most comprehensive tests used to detect causal variants, wholeexome sequencing (WES), allows analysis of not only the 30 million base pairs of DNA encoding the proteins, but also the sequences that regulate this part. ${ }^{1}$

On evaluating patients recently prompted by clinicians for WES analysis, I thought it is necessary to highlight some points. While the minimum cost of each WES test is about $\$ 600$ in many developed countries, it is in the range of $\$ 1500-2500$ in this country. This high cost can be considered reasonable, considering the period when WES was first discovered; but it is still at a level that is unafforable for most patients, especially in developing countries. In addition to its high cost, WES also brings forth some problems in terms of reporting and interpretation. For example, secondary findings may be discovered incidentally in the patients' genome in WES test. Although there are specific guidelines for these incidental findings that are recommended to be reported in the literature, uncertainty remains regarding reporting some important genes other than those included in this guide. ${ }^{2}$

In the analysis phase of this test, thousands of variants of uncertain clinical significance (VUS) are identified in both genes, known to be associated with phenotype and in many candidate genes. Many of these VUS continue to be VUS in the presence of all scientific evidence and even if co-segregation analyses are performed. These variants need to be evaluated by a really well-trained team in order to interpret them and establish an accurate genotype-phenotype relationship. A causal variant, particularly in candidate genes, is likely to be overlooked in this gruelling journey that resembles a needle search in a haystack.

Unfortunately, today there are still no clear criteria for selecting patients for WES analysis, performed in many genetic diagnosis laboratories. In cases that do not fit a specific genetic disease pattern and have clinically multiple differential diagnoses, individuals for whom a specific genetic test is not avail- able for the diagnosis of the disease, and complex cases whose causal genes have not been identified as a result of previous tests, and also in diseases where heterogeneous genetic causes are thought to play a role in the etiopathogenesis, it may be appropriate to orderWES.

Although the appeal of this test, which allows the examination of all coding regions of the genome, continues to increase dayby-day for clinicians. Studies have shown that the rate of diagnosis by WES analysis in clinical series is $22-26 \%{ }^{3}$ It is hoped that WES will be requested for justifiable reasons and will not be preferred as the first-choice test in the diagnostic adventure of clinicians.

\section{CONFLICT OF INTEREST:}

The author declared no conflict of interest.

\section{AUTHOR'S CONTRIBUTION:}

ND: Conception, design, acquisition, analysis, interpretation, drafting and revising it critically for important intellectual content, and final approval of the version to be published.

\section{REFERENCES}

1. Rabbani B, Tekin M, Mahdieh N. The promise of wholeexome sequencing in medical genetics. J Hum Genet 2014; 59(1):5-15. doi: 10.1038/jhg.2013.114.

2. Kalia SS, Adelman K, Bale SJ, Chung WK, Eng C, Evans JP, et al. Recommendations for reporting of secondary findings in clinical exome and genome sequencing, 2016 update (ACMG SF v2.0): A policy statement of the American College of Medical Genetics and Genomics. Genet Med 2017; 19(2):249-55. doi.org/10.1038/gim.2016.190.

3. Retterer K, Juusola J, Cho MT, Vitazka P, Millan F, Gibellini F, et al. Clinical application of whole-exome sequencing across clinical indications. Genet Med 2016; 18(7): 696-704. doi: 10.1038/gim.2015.148.

Neslihan Duzkale

Department of Medical Genetic, Ankara Diskapi Yildirim

Beyazid Hospital, Ankara, Turkey

Correspondence to: Dr. Neslihan Duzkale, Department of Medical Genetic, Ankara Diskapi Yildirim Beyazid Hospital, Ankara, Turkey

E-mail: neslihanduzkale@gmail.com

Received: April 05, 2021; Revised: July 27, 2021; Accepted: August 08, 2021

DOI: https://doi.org/10.29271/jcpsp.2022.02.265 